\title{
Clinical features and treatment outcomes of resistant acromegaly patients: a single center study
}

\author{
DEMIR Ö., CANPOLAT GÖKÇAY A., AYDOĞAN B.İ., KESKIN Ç., CANLAR Ş., ŞAHİN M., EMRAL R., GÜLLÜ S., TONYUKUK GEDIKK V., UYSAL A.R., \\ ÇORAPÇIOĞLUD.
}

Ankara University Faculty of Medicine, İbn-i Sina Hospital, Department of Endocrinology and Metabolism , Ankara, TURKEY

\section{Objectives:}

Disease control in acromegaly can be achieved by surgery, medical treatment and radiotherapy either alone or in combination. The acromegaly patients whom tumor shrinkage can not be provided or Growth Hormone $(\mathrm{GH})$ levels do not decrease under multiple treatment modalities are designated as resistant acromegaly. We aimed in our study to evaluate the clinical features of resistant acromegaly patients and determine their responds to different treatment modalities.

\section{Methods:}

47 acromegaly patients were enrolled between 2007 and 2015 in this study. 18 of patients ( 10 men and 8 women) were accepted as resistant acromegaly. Resistant cases were defined according to their clinical course under somatostatin analogs, radiotherapy, dopamin agonists and pegvisomant therapy for at least six months of duration. Their clinical, radiological and pathological features at the time of diagnosis were evaluated.

\begin{tabular}{lc}
\hline Parameters & $\mathbf{n = 1 8}$ patients \\
\hline $\begin{array}{l}\text { Radiotherapy } \\
\text { gamma- knife } \\
\text { conventional rt (5000 cGY) }\end{array}$ & $1(0-1)$ \\
GH levels (at diagnosis) & 2 \\
Cavernous sinus invasion & $54(11-226) \mathrm{ng} / \mathrm{ml}$ \\
Pitüitary insufficiency & 7 \\
\hline
\end{tabular}

\section{Results:}

The median age, median tumor size and mean IGF-1 levels at diagnosis were found 36,5 (28-62), $21 \mathrm{~mm}(12-70)$ and 1184 $\pm 567 \mathrm{ng} / \mathrm{ml}$ respectively. Mean IGF-1 (1184 \pm 567 versus $486 \pm 89$ ) and GH levels 54 (11-226) versus 12 (4- 38) were different between resistant group and responder group $(p<0,01)$. The mean numbers of their operation and radiation were found $2(0-3)$ and $1(0-1)$. Of these 18 procedures, 15 were transsphenoidal procedures and 3 involved transfrontal surgery. Histological evaluation revealed exhibition of sparse granular staining in 8 patients.

Long acting somatostatin analog therapy dose was increased in 3 patients. Cabergolin (0,5-2 mg/week) and pegvisomant therapy were added to their somatostatin analog therapy in 5 and 10 patients, respectively. The mean follow-up was $18 \pm 4$ months. There were no difference found between these tree treatment modalities. IGF-1 normalisation was achieved overall in $94 \%$ of resistant acromegaly patients.

Resistance to traditional treatment options in acromegaly represents $25 \%$ of whole cases(1).

We found a similar ratio as $39 \%$ in our case series. Resistant group was found to be diagnosed at younger age, with greater dimensions of tumor and found to have more sparse granular staining compatible with literature.

We could not find any differences between IGF-1 levels. It is also a debate as whether which treatment option is suitable for resistant patients. 